\title{
Pemphigus Vulgaris in Adolescence: a Case Report
}

\author{
Pemphigus Vulgar en la Adolescencia: Reporte de un Caso \\ Jean Paulo Rodolfo Ferreira*; Paula Caetano Araújo*; Marcos Tadeu Adas Saliba*; \\ Renata Bianco Consolaro ${ }^{* * *} \&$ Cléa Adas Saliba Garbín ${ }^{* \star *}$
}

FERREIRA, J. P. R.; ARAÚJO, P. C.; SALIBA, M. T. A.; CONSOLARO, R. B. \& GARBíN, C. A. S. Pemphigus vulgaris in adolescence: a case report. Int. J. Odontostomat., 7(2):215-220, 2013.

ABSTRACT: Pemphigus vulgaris is an autoimmune disease, normally associated with oral lesions that generally affects patients aged 40 - 60 years. The aim of this study was to report a case of pemphigus vulgaris presenting at an uncommon age with advanced periodontal disease, and to describe the treatment performed from the time of diagnosis through oral environment restoration and follow-up monitoring. One gingival vesicular lesion was biopsied. After the histological confirmation of pemphigus vulgaris, the patient was referred to a specialist for treatment of this systemic disease. With the improvement of the patient's clinical condition, teeth were extracted and oral rehabilitation was performed. The patient is being followed and is taking the appropriate medication. A direct immunofluorescence test was performed, but the patient had already started treatment with immunosuppressive medication at the time of the perilesional biopsy. The result of this test was negative. Pemphigus vulgaris manifests as extremely painful and persistent oral lesions. Thus, patient motivation to maintain oral health, preventive measures and the promotion of oral health, should be prioritized to avoid the worsening of the patient's systemic condition.

KEY WORDS: periodontal diseases, pemphigus, autoimmune diseases, adolescent, pathology.

\section{INTRODUCTION}

Pemphigus encompasses four related diseases with autoimmune etiopathogeneses: Pemphigus vulgaris, vegetans, erythematosus, and foliaceus. Only the vulgaris and vegetans types attack the oral mucosa, and pemphigus vulgaris is the most prevalent type (Neville et al., 2009). These rare diseases involve the mucosa and skin through the disintegration of cellular adherence (acantholysis), resulting in intradermal bullous disease (Maruani et al., 2008; Neville et al.). The nasal mucosa, palpebral area, genitalia, pharynx, esophagus, and larynx can also be affected (Nishikawa et al., 1996). The annual incidence of pemphigus is around 0,1 - 0,5/100,000 individuals (Amagai et al., 1992; Neville et al.). This disease has a serious prognosis and may be fatal if it is not diagnosed and treated in the initial phase (Ahmed et al., 1980).
Pemphigus vulgaris is characterized by alterations in the intracellular links of the Malpighian stratum spinosum, where some structures become antigenic and stimulate the production of autoantibodies, mainly immunoglobulin $\mathrm{G}$ ( $\mathrm{IgG}$ ) (Neville et al.). The etiology of these modifications is not currently known, but the target of the autoantibodies is desmoglein-3 (Dsg3), a glycoprotein that interacts with components of the dense plaque of the desmosomes. The consequence of this interaction is damage to the links among epidermal cells, which creates suprabasal slots that appear clinically as bullous disease (Kalish, 2000; Neville et al.).

Generally, this disease affects patients aged 40 - 60 years; shows a strong genetic association; and is

\footnotetext{
Doctor degree candidate of Preventive and Social Dentistry Post-Graduation Program - Department of Infant and Social Dentistry, Faculty of Dentistry, Araçatuba Dental School, UNESP, Araçatuba, São Paulo State, Brazil.

* Full Professor - Implant Dentistry and Surgery Disciplines, Faculty of Dentistry, Integrated Schools of Adamantina, FAI, Adamantina, São Paulo State, Brazil.

Substitute Professor - Department of Pathology and Clinical Propaedeutic, Faculty of Dentistry, Araçatuba Dental School, UNESP, Araçatuba, São Paulo State, Brazil.

**** Coordinator of Public Health Post-graduation Program - Department of Infant and Social Dentistry, Faculty of Dentistry, Araçatuba Dental School, UNESP, Araçatuba, São Paulo State, Brazil.
} 
more prevalent in certain ethnic groups, such as Ashkenazi Jews and populations from the Mediterranean and South Asia (Gellis \& Glass, 1941). The initial manifestation of pemphigus vulgaris is commonly in the oral mucosa, followed by the appearance of cutaneous lesions (Neville et al.). Thus, dentists must be alert to the manifestation of these disease signs in their patients to achieve the most favorable treatment outcome and prognosis.

Oral lesions of pemphigus vulgaris appear clinically as localized or diffuse bubbles that rupture quickly, resulting in areas with painful erosions and ulcerations (Mignogna et al., 2001). Any region of the oral mucosa can be affected, but the soft palate, labial and jugal mucosae, ventral surface of the tongue, and gingiva are affected most commonly (Neville et al.). Cutaneous lesions may be isolated or generalized flaccid blisters that express citrine or hemorrhagic liquid when ruptured, resulting in expressive erosive areas (Ahmed et al.) that bleed readily and usually develop a crust (Bickle et al., 2002). The repair of cutaneous lesions causes no scarring, but residual hyperpigmentation is often present.

The diagnosis of pemphigus vulgaris can be made based on the clinical and histopathological characteristics of the disease. A clinical diagnosis is often based on testing for Nikolsky's sign, in which friction is applied to a cutaneous or mucosal area with normal appearance using digital palpation or a blunt instrument; the local reaction of the mucosa is evaluated, with appearance of a hemorrhagic bubble indicating positivity (Neville et al.). In patients with pemphigus vulgaris, the result of this test is the clinical manifestation of acantholysis, although this finding is not pathognomonic for the disease (Darling \& Daley, 2006). However, histopathological examinations with conventional staining and indirect and direct immunofluorescence are essential to obtain a definitive diagnosis of pemphigus (Galan et al., 2009).

The treatment of pemphigus vulgaris consists of immunosuppressive therapy with systemic corticosteroids. Before the introduction of corticosteroids, this disease was associated with a mortality rate of nearly $100 \%$. This rate has decreased significantly due to the use of corticosteroids, antibiotics, and antifungal medications that prevent secondary infections (Neville et al.).

Oral hygiene and recommended diet should be included in treatment plans for patients with pemphigus vulgaris because the oral lesions of this disease are persistent and painful, making proper toothbrushing difficult and resulting in plaque accumulation and an increased incidence of periodontal disease (Thorat et al., 2010). The aim of this study was to present a case of pemphigus vulgaris with an uncommon age at presentation accompanied by advanced periodontal disease, describing the treatment executed from the time of diagnosis through the restoration of the oral $\mathrm{e}$ nvironment and follow-up.

\section{CASE REPORT}

A 15-year-old melanodermatous male patient received periodontal treatment at the Integrated Schools of Adamantina, São Paulo State, Brazil. He was dissatisfied with his oral status and expressed embarrassment due to the appearance of his teeth, gingival bleeding and burning sensation, frequent pain, halitosis, partial loss of chewing function, and tooth sensitivity during the ingestion of hot and cold foods or liquids (Fig. 1).

Clinical examination revealed advanced periodontitis with a periodontal pocket depth $>5.5 \mathrm{~mm}$, tooth mobility, furcation involvement, and gingival recession $>3.5 \mathrm{~mm}$. Intraoral physical examination showed the presence of lesions and large ulcers with erythematous halos and blood exudate in the maxillary buccal gingiva. The free gingival aspect was red and fragile, with epithelial desquamation and bleeding. Extraoral examination revealed no lymphadenopathy, the patient's medical history contained no relevant information, and laboratory examinations (blood cell count and HIV test) performed immediately upon the patient's presentation were unremarkable.

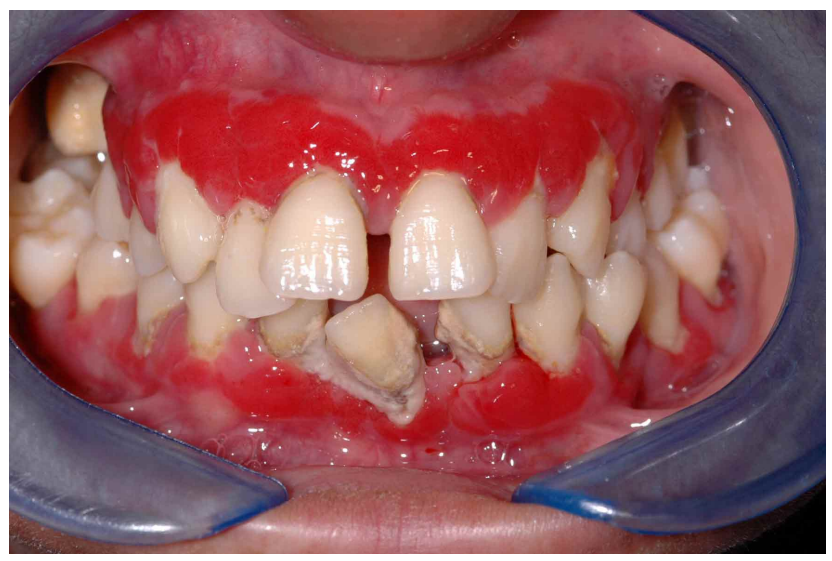

Fig. 1. The patient's clinical condition at presentation. 


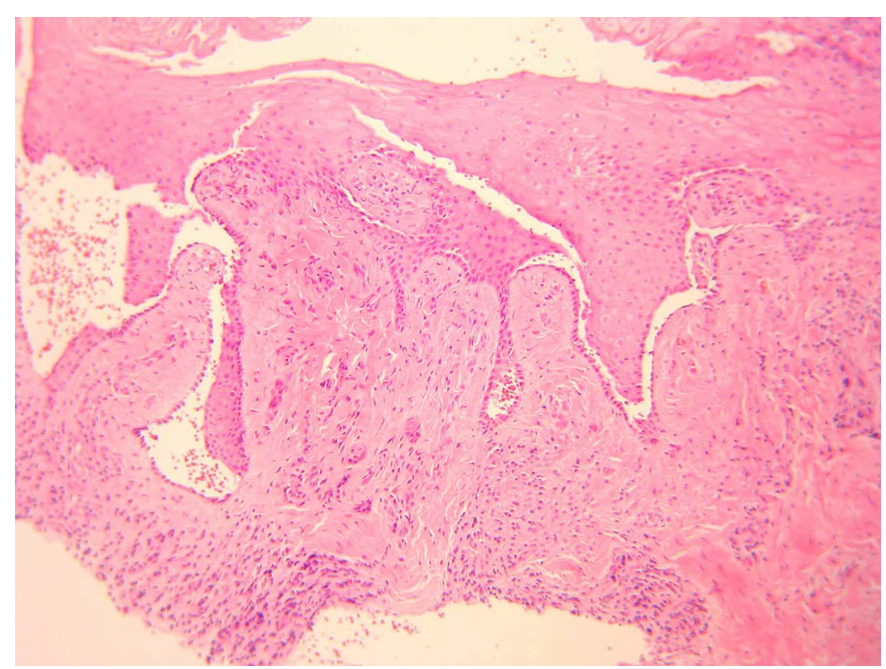

Fig. 2. Stratified squamous epithelium with suprabasal intraepithelial cracking.

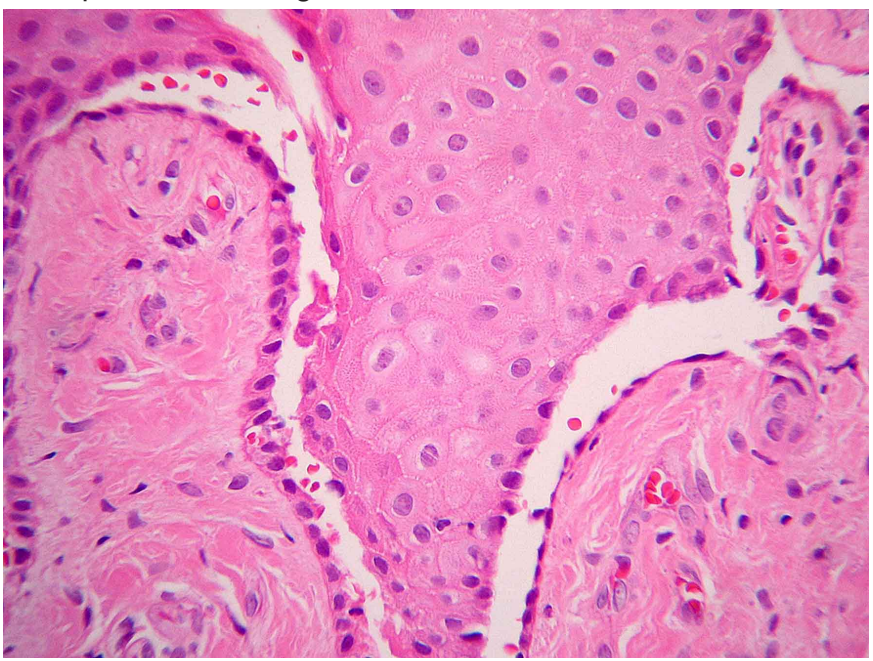

Fig. 3. Basal layer of the epithelial tissue connected to the conjunctive tissue.

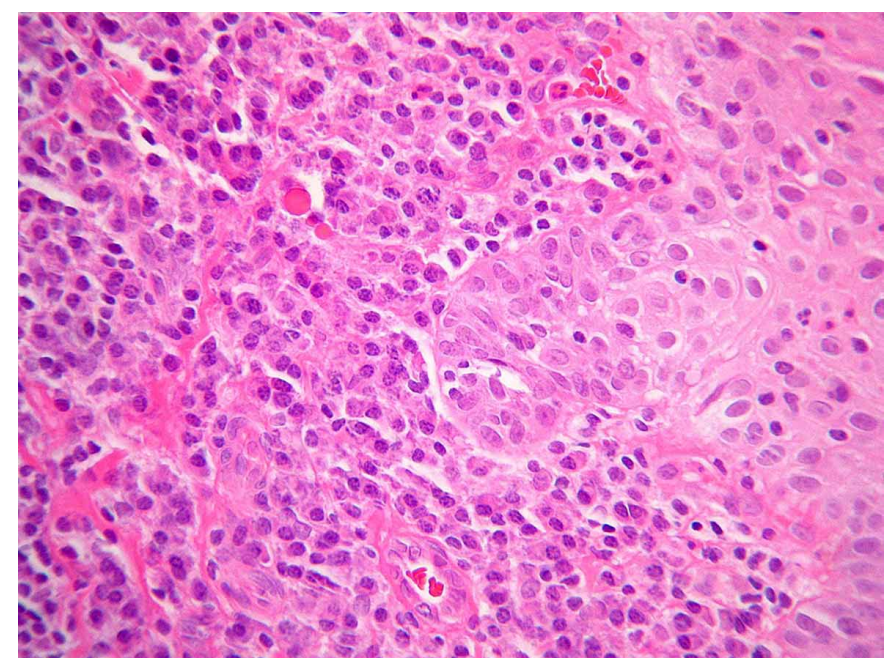

Fig. 4. Mononuclear inflammatory infiltrate permeated by Russel corpuscles.
First, the oral environment was restored by tooth crown scaling using Gracey (\#5-6, \#78, \#11-12, \#13-14) and McCall (\#17-18) curettes, followed by polishing using rubber cups and prophylaxis paste. The patient was administered chlorhexidine $(0.12 \% ; 15 \mathrm{ml}$ twice daily for 15 days). As these procedures yielded no improvement in the aspect of the lesions, a biopsy was performed on a gingival bullous lesion located in keratinized mucosa between teeth \#13 and \#14. Microscopic incisions revealed that the oral mucosa was comprised of stratified squamous epithelium with suprabasal intraepithelial cracking (Fig. 2). The basal layer of the epithelial tissue was connected to the conjunctive tissue, beneath which lay conjunctive tissue with abundant collagen and numerous cells showing mild mononuclear inflammatory process, predominantly lymphoplasmocytic (Fig. 3). In other areas, the epithelial tissue evidenced no intraepithelial cracking, but the subjacent conjunctive tissue showed intense lymphoplasmocytic mononuclear inflammatory infiltrate permeated by some hyaline Russel corpuscles (Fig. 4).

After histological confirmation of the diagnosis of pemphigus vulgaris, the patient was referred to a specialist for treatment of the systemic disease. The management of Nikolsky's sign was not performed due to the patient's painful symptom status to avoid the manifestation of additional lesions. After the patient's clinical status had improved, teeth 26 , 31, 32, 36, 37, 41, and 46 were extracted (Fig. $5)$ and oral rehabilitation was performed.

We continue to clinically follow the patient, who is on a regimen of meticorten $(20 \mathrm{mg} / \mathrm{d})$ and thalidomide ( 1 capsule/d). To maintain proper periodontal status, the patient periodically undergoes oral health maintenance procedures at the Periodontics Dental Offices of the Integrated Schools of Adamantina. Is important to highlight that direct immunofluorescence testing was performed in this case, but the results were negative because the patient had already started immunosuppressive drug therapy at the time of biopsy. The ethical principles of the Helsink declaration were followed and the Informed Consent Term was assigned by the responsible of the minor. 


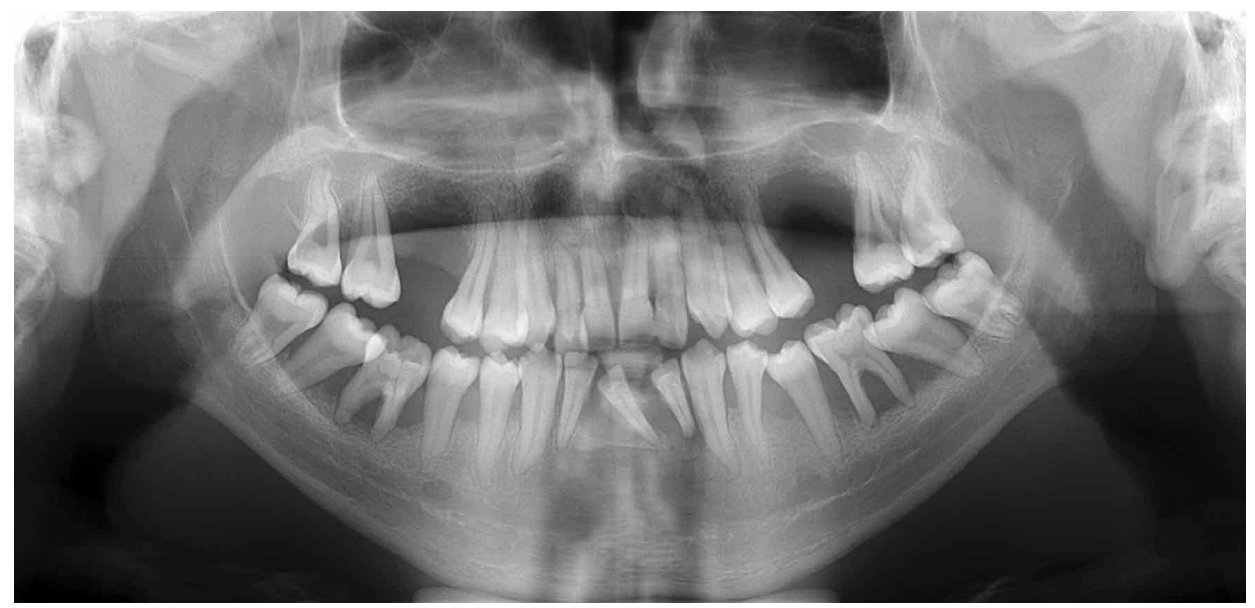

Fig. 5. Radiographic image of the patient before extractions.

\section{DISCUSSION}

Pemphigus vulgaris is normally associated with oral lesions; this autoimmune disease first manifests in the oral mucosa in the majority of cases $(70 \%)$, and this is the sole region of manifestation in more than $50 \%$ of patients (Lamey et al., 1992). In the case reported here, the patient showed bullous disease only in the oral mucosa; no cutaneous lesion was present on his body to aid in diagnosis.

Although pemphigus generally affects individuals aged 40-60 years (Bickle et al.), the case reported here was unusual because pemphigus vulgaris was diagnosed in a 15-year-old patient.

The first signs of the disease that led the adolescent to seek dental treatment were gingival burning, halitosis, and the appearance of bullous lesions that preceded ulcerations in the oral cavity. Robinson et al. (1997) and Fassmann et al. (2003) reported that the first sign of the disease can appear in the oral mucosa about 2 years before the outbreak of systemic illness.

Other signs mentioned by the patient were pain and the persistence of oral lesions, which made it difficult to maintain proper oral hygiene. Such difficulty typically results in plaque accumulation, which makes pemphigus vulgaris a causal factor of periodontitis. Periodontal disease is multifactorial, and systemic conditions can act as risk factors for its appearance (Renvert, 2003; Renvert et al., 2003; Abrahamsson et al., 2008; Andrades et al., 2011; Lutfioglu et al., 2012; Merello \& Oliva, 2012). Thus, dentists have an important role in the early diagnosis of pemphigus vulgaris, and physicians are essential for the continuous treatment and follow-up of patients with this autoimmune disease.

In the present case, histopathological examination was performed on a biopsy specimen from one of the bubble lesions. According to Schneider \& Schneider (1998), biopsy is the most reliable method for the definitive diagnosis of pemphigus vulgaris. Microscopic incisions revealed the oral mucosa was comprised of stratified squamous epithelium with suprabasal intraepithelial cracking. The basal layer of the epithelial tissue was connected to the conjunctive tissue, and subjacent conjunctive tissue was very well collagenized and cellularized with mild mononuclear inflammatory infiltrate, predominantly lymphoplasmocytic. In other areas, the epithelial tissue showed no intraepithelial cracking, but the subjacent conjunctive tissue showed intense lymphoplasmocytic mononuclear inflammatory infiltrate permeated by eventual hyaline Russel corpuscles. Such findings can confirm the diagnosis of pemphigus, but this can also be achieved by immunofluorescence (Magro et al., 2003) to identify the presence of autoantibodies, tissue complement, and fibrinogen; and to assess the severity of the disease, evaluate the quantity of antibodies, and control antibody levels during treatment (Sonis et al., 1995). Although a diagnosis can be made using either of these two techniques, Challacombe et al. (2001) considered it essential to perform both histopathological and immunological examinations of tissues obtained by biopsy. 
In the present case, we performed direct immunofluorescence testing while the patient was receiving drug treatment. The result of the examination was negative for pemphigus vulgaris, using the following markers: fibrinogen, C3 fragment of the complement system, and human $\lg \mathrm{A}, \lg G$ and $\lg M$. We suspect that the false negative result was due to the use of immunosuppressive drugs. However, Sonis et al., observed that immunofluorescence techniques, especially the indirect form, can yield negative results in the initial phase of the disease, when lesions are typically restricted to the oral cavity, as in the present case.

After the diagnosis of pemphigus vulgaris in our patient, appropriate drug therapy was chosen by the physician to improve his clinical status. Pemphigus vulgaris treatment is based on the systemic use of oral corticosteroids (Bystryn \& Steinman, 1996; Motta et al., 2009). However, studies have shown that the continuous use of steroids is the main cause of sepsis and pulmonary embolism (Bystryn, 1984). The topical application of steroids is insufficient in patients with this systemic autoimmune disease (Mignogna et al.). Thus, the long-term use of corticosteroids in patients with pemphigus vulgaris can result in severe collateral effects, such as reduced resistance to infection, hypertension, high blood glucose level, hydroelectric disturbance, muscular disease, osteoporosis, suppression of the hypothalamic-cortical-adrenal axis, and Cushing syndrome (Neville et al.). These effects have prompted an ongoing search for treatment techniques with low doses of steroids to maintain the status of patients with pemphigus vulgaris, in combination with drugs that can reduce the need for steroids (Bystryn et al.). These drugs include azathioprine, cyclophosphamide, methotrexate, mofetil, tetracycline, dapsone, intravenous immunoglobulin, plasmatic exchange, immunophoresis, and intralesional steroids. The patient in our case is on a continuous regimen of meticorten $(20 \mathrm{mg} / \mathrm{d})$ and thalidomide (1 capsule/d).

Education and preventive practices that emphasize motivation to maintain oral health are essential for patients with pemphigus vulgaris. Toothbrushing supervision, education about the importance of dental floss use, the use of chlorhexidine mouthwash, and frequent dental visits should be part of patient management. Physicians have an important role in explaining the oral effects of this autoimmune disease to the patient. Early diagnosis and appropriate treatment, in combination with the maintenance of oral and systemic health, can promote a favorable prognosis for patients with pemphigus vulgaris, improving their well-being and quality of life.

Patients with pemphigus vulgaris should be guided in the continuous maintenance of oral health by dentists or periodontic experts. This autoimmune disease manifests as extremely painful and persistent lesions in the oral cavity. Thus, patient motivation to maintain oral health, preventive measures, and the promotion of oral health should be prioritized to avoid the worsening of the patient's systemic condition with the development of periodontitis.

\section{ACKNOWLEDGEMENTS}

The authors acknowledge the Coordination for the Improvement of Higher Education Personnel (CAPES) for providing a master's degree scholarship to Paula Caetano Araújo.

FERREIRA, J. P. R.; ARAÚJO, P. C.; SALIBA, M. T. A.; CONSOLARO, R. B. \& GARBíN, C. A. S. Pemphigus vulgar en la adolescencia: reporte de un caso. IInt. J. Odontostomat., 7(2):207-213, 2013.

RESUMEN: El pemphigus vulgar es una enfermedad autoinmune, que normalmente está asociada con lesiones orales que afectan a pacientes de 40 a 60 años. El objetivo de este trabajo es presentar un caso de pénfigo vulgar en una edad poco común con enfermedad periodontal avanzada, así como describir el tratamiento realizado desde el momento del diagnóstico, restauración de la salud oral y el seguimiento del monitoreo. Se realizó la biopsia de una lesión vesicular gingival. Después de la confirmación histológica del pemphigus vulgar, el paciente fue presentado a un especialista para el tratamiento de esta enfermedad sistémica. Con la mejora de la condición clínica del paciente, los dientes fueron extraídos y se realizó la rehabilitación oral. El paciente está siendo acompañado y tomando la medicación apropiada. Fue realizado el exámen de inmunofluorescencia directa, pero el paciente ya había comenzado el tratamiento con medicamentos inmunosupresores en el momento de la biopsia perilesional. El resultado de este examen fue negativo. El pemphigus vulgar se manifiesta en forma de lesiones orales extremadamente dolorosas y persistentes. Por lo tanto, la motivación del paciente para mantener la salud oral, las medidas de prevención y promoción de la salud oral deben ser priorizadas para evitar el empeoramiento de la condición sistémica del paciente.

PALABRAS CLAVE: enfermedades periodontales, pemphigus vulgar, enfermedades autoinmunes, adolescente, patología. 


\section{REFERENCES}

Abrahamsson, K. H.; Wennström, J. L. \& Hallberg, U. Patients' views on periodontal disease; attitudes to oral health and expectancy of periodontal treatment: a qualitative interview study. Oral Health Prev. Dent., 6(3):209-16, 2008.

Ahmed, A. R.; Graham, J.; Jordan, R. E. \& Provost, T. T. Pemphigus: current concepts. Ann. Intern. Med., 92(3):396-405, 1980.

Amagai, M.; Karpati, S.; Prussick, R.; Klaus-Kovtun, V. \& Stanley, J. $\mathrm{R}$. Autoantibodies against the amino-terminal cadherin-like binding domain of pemphigus vulgaris antigen are pathogenic. J. Clin. Invest., 90(3):919-26, 1992.

Andrades, K. M. R.; Oliveira, G. B.; Àvila, L. F. C.; Odebrecht, M. R. \& Miguel, L. C. M. Asociación de los Índices de Glucemia, Hiposalivación y Xerostomía en Pacientes Diabéticos Tipo 1. Int. J. Odontostomat., 5(2):185-90, 2011.

Bickle, K.; Roark, T. R. \& Hsu, S. Autoimmune bullous dermatoses: a review. Am. Fam. Physician, 65(9):1861-70, 2002.

Bystryn, J. C. Adjuvant therapy of pemphigus. Arch. Dermatol.,120(7):941-51, 1984.

Bystryn, J. C. \& Steinman, N. M. The adjuvant therapy of pemphigus: an update. Arch. Dermatol., 132(2):203-12, 1996.

Challacombe, S. J.; Setterfield, J.; Shirlaw, P.; Harman, K.; Scully, C. \& Black, M. M. Immunodiagnosis of pemphigus and mucous membrane pemphigoid. Acta Odontol. Scand., 59(4):226-34, 2001.

Darling, M. R. \& Daley, T. Blistering mucocutaneous diseases of the oral mucosa: a review: part 2. Pemphigus vulgaris. J. Can. Dent. Assoc., 72(1):63-6, 2006.

Fassmann, A.; Dvoráková, N.; Izakovıcová Hollá, L.; Vanuk, J. \&, Wotke, J. Manifestation of pemphigus vulgaris in the orofacial region: case report. Scr. Med., 76:55-62, 2003.

Galan, A.; Hui, P. \& McNiff, J. M. Absence of human herpesvirus 8 in pemphigus and bullous pemphigoid. Int. J. Clin. Exp. Pathol., 2(5):456-62, 2009

Gellis, S. \& Glass, F. A. Pemphigus: a survey of one hundred and seventy patients admitted to Bellevue Hospital from 1991 to 1941. Arch. Dermatol. Syphil., 44:321-36, 1941.

Kalish, R. S. Pemphigus vulgaris: the other half of the story. J. Clin. Invest., 106(12):1433-5, 2000.

Lamey, P. J.; Rees, T. D.; Binnie, W. H.; Wright, J. M.; Rankin, K. V. \& Simpson, N. B. Oral presentation of pemphigus vulgaris and its response to systemic steroid therapy. Oral Surg. Oral Med. Oral Pathol., 74(1): 54-7, 1992.

Lutfioglu, M.; Sakallioglu, U.; Sakallioglu, E. E.; Baris, S. \& Gurgor, P. The impact of dietary induced hyperparathyroidism on healthy and diseased periodontia: an experimental study in rats. J. Clin. Periodontol., 39(3):264-71, 2012.

Magro, C. M.; Morrison, C.; Pope-Harman, A.; Rothrauff, S. K. \&
Ross, P. Jr. Direct and indirect immunofluorescence as a diagnostic adjunct in the interpretation of nonneoplastic medical lung disease. Am. J. Clin. Pathol., 119(2):279-89, 2003.

Maruani, A.; Machet, M. C.; Carlotti, A.; Giraudeau, B.; Vaillant, L. \& Machet, L. Immunostaining with antibodies to desmoglein provides the diagnosis of drug-induced pemphigus and allows prediction of outcome. Am. J. Clin. Pathol., 130(3):369-74, 2008.

Merello, L. M. \& Oliva, M. P. Obesidad y su Relación con las Patologías Periodontales: una Revisión Narrativa. Int. J. Odontostomat., 6(2):235-9, 2012.

Mignogna, M. D.; Lo Muzio, L. \& Bucci, E. Clinical features of gingival pemphigus vulgaris. J. Clin. Periodontol., 28(5):489-93, 2001.

Motta, A. C.; Domaneschi, C.; Komesu, M. C.; Souza Cda, S. Aoki, V. \&, Migliari, D. A. Double-blind, crossover, placebo-controlled clinical trial with clobetasol propionate in desquamative gingivitis. Braz. Dent. J., 20(3):231-6, 2009.

Neville, B. W.; Damm, D. D.; Allen, C. M. \& Bouquot, J. E. Oral \& Maxillofacial Pathology. 3rd ed. St. Louis, Saunders Elsevier, 2009.

Nishikawa, T.; Hashimoto, T.; Shimizu, H.; Ebihara, T. \& Amagai, M. Pemphigus: from immunofluorescence to molecular biology. $J$. Dermatol. Sci., 12(1):1-9, 1996.

Renvert, S. Destructive periodontal disease in relation to diabetes melitus, cardiovascuiar diseases, osteoporosis and respiratory diseases. Oral Health Prev. Dent., 1 Suppl. 1:341-57, 2003.

Renvert, S.; Öhrn, K. \& Echeverria, J. Session A - Systemic health and destructive periodontal diseases. Oral Health Prev. Dent., 1 Suppl. 1:358-9, 2003.

Robinson, J. C.; Lozada-Nur, F. \& Frieden, I. Oral pemphigus vulgaris: a review of the literature in a report of the management of 12 cases. Oral Surg. Oral Med. Oral Pathol. Oral Radiol. Endod., 84(4):349-55, 1997.

Schneider, L. C. \& Schneider, A. E. Diagnosis of oral ulcers. Mt. Sinai J. Med., 65(5-6):383-7, 1998.

Sonis, S. T.; Fazio, R. C. \& Fang, L. Principles and practice of oral medicine. $2^{\text {nd }}$ ed. Philadelphia, W.B. Saunders, 1995.

Thorat, M. S.; Raju, A. \& Pradeep, A. R. Pemphigus vulgaris: effects on periodontal health. J. Oral Sci., 52(3):449-54, 2010.

Correspondence to:

Cléa Adas Saliba Garbín

Street José Bonifácio, 1193

Vila Mendonça, Araçatuba-SP

Zip Code: 16015-050

BRAZIL

\section{Email:cgarbin@foa.unesp.br} paulinhacaetano@hotmail.com

Received: 29-01-2013

Accepted: 17-06-2013 